\title{
PEMBUATAN KOMPOR LISTRIK UNTUK PRODUKSI BATIK TULIS DI DESA TAWANGARGO KECAMATAN KARANGPLOSO KABUPATEN MALANG
}

\author{
Elik Murni Ningtias Ningsih ${ }^{1 *}$, Yusuf Arif Wibowo Putra ${ }^{2}$, Akhmad Rizal Fanani ${ }^{3}$, \\ Fakhri Bakti Utomo \\ ${ }^{1}$ Program Studi Agroteknologi, Fakultas Pertanian, Universitas Widyagama Malang \\ ${ }^{2}$ Program Studi Akuntansi, Fakultas Ekonomi dan Bisnis, Universitas Widyagama Malang \\ ${ }^{3}$ Program Studi Teknik Mesin, Fakultas Teknik, Universitas Widyagama Malang \\ ${ }^{4}$ Program Studi Teknik Elektro, Fakultas Teknik, Universitas Widyagama Malang \\ *Email Korespondensi: elik_uwg@yahoo.co.id
}

Submitted : 2 Oktober 2020; Revision : 19 November 2020; Accepted : 8 Februari 2021

\begin{abstract}
ABSTRAK
Batik adalah salah satu kekayaan budaya asli Indonesia yang telah diwariskan oleh nenek moyang, dan batik merupakan kain bergambar yang pembuatannya secara khusus. Pengolahannya diproses dengan cara tertentu yang memiliki kekhasannya tersendiri. Berdasarkan studi yang dilakukan di salah satu Usaha Mikro Kecil Menengah (UMKM) di Karang Ploso, Kabupaten Malang bernama "Batik Kalosa", bahwa produsen batik tulis memiliki kendala dalam proses mencairkan malam serta mempertahankan level kecairan malam. Selama ini kompor yang digunakan untuk mencairkan malam menghasilkan aroma gas yang mengganggu proses pembuatan batik. Maka peneliti membuat sebuah inovasi pembuatan kompor listrik yang bertujuan untuk meningkatan kehandalan produksi batik dan proses produksi batik tulis. Metode penelitian dimulai dari survei lokasi, dilanjutkan pembuatan kompor listrik, pengujian peralatan dan pengaplikasian alat selama 7 hari. Hasil yang didapat bahwa pencairan malam menggunakan kompor listrik lebih cepat 5 menit dibandingkan menggunakan kompor konvensional, dan tidak menimbulkan asap hasil pembakaran.
\end{abstract}

Kata kunci : Batik Tulis, Usaha Kecil Menengah, Kompor Listrik, UMKM

\section{ABSTRACT}

Batik is one of Indonesia's original cultural treasures that has been passed down by our ancestors, and batik is a printed cloth that is specially made. The processing is processed in a certain way which has its peculiarities. Based on a study conducted at one of the Small and Medium Enterprises (SMEs) in Karang Ploso, Malang Regency named "Batik Kalosa", written batik producers have problems in the process of defrosting nights and maintaining the level of night liquid. So far, the stove used to melt the wax produces a gas aroma that disturbs the batik-making process. So the researchers made an innovation in the manufacture of electric stoves which aims to increase the reliability of batik production and the batik production process. The research method started with a location survey, continued with the manufacture of an electric stove, testing the equipment and applying the tools for 7 days. The results show that the melting of the night using an electric stove is 5 minutes faster than using a conventional stove, and does not cause smoke from combustion.

Keywords : Written Batik, Small and Medium Enterprises, Electric Stoves, SMEs

\section{PENDAHULUAN}

Indonesia merupakan negara dengan keanekaragaman suku bangsa, Bahasa dan budaya. Salah satu kebudayaan Indonesia yang mendunia yaitu batik. Batik Indonesia, sebagai keseluruhan teknik, teknologi, serta pengembangan motif dan budaya yang terkait, oleh UNESCO telah ditetapkan sebagai Warisan Kemanusiaan untuk Budaya Lisan dan Nonbendawi (Masterpieces of the Oral and Intangible Heritage of Humanity) sejak 2 
Oktober 2009 (Soesanto, 1980; Ari and Nusantara, 2011; Lusianti and Rani, 2012; Damayanti and Latifah, 2017; Kartika and Mujanah, 2017).

Kontribusi batik sebagai salah satu industri tekstil juga dinilai cukup besar. Terbukti nilai ekspor batik dari tahun ke tahun semakin melonjak tinggi. Hal ini dipertegas oleh mantan Direktur Jenderal Pengembangan Ekspor Nasional Kementerian Perdagangan, Gusmardi Bustami menyebutkan bahwa ekspor batik ke mancanegara cukup besar atau $10 \%$ dari total ekspor tekstil yang mencapai US\$ 12 miliar pada tahun 2012. Hal ini tidak jauh karena adanya pemberdayaan home industry ataupun Usaha Mikro Kecil Menengah (UMKM) yang memproduksi kerajinan batik yang saat ini jumlahnya juga semakin banyak seiring berjalannya waktu (Andayani and Tjahyono, 2014; Damayanti and Latifah, 2017; Khamid and Hasyim, 2017; Nurhayata, 2018; Asyari and Umar, 2019).

Salah satu UMKM di Daerah Karangploso yang berada di Kabupaten Malang adalah "Batik Kalosa" salah satu dari beberapa home industry yang berusaha melestarikan kebudayaan khas Indonesia yaitu batik tulis. Di UMKM ini terdapat berbagai masalah, diantaranya proses pencairan malam untuk batik tulis yang membutuhkan waktu relatif lama dan aroma asap hasil pembakaran menggunakan kompor konvensioanal yang tidak baik bagi kesehatan.

Dari permasalahan diatas peneliti membuat sebuah gagsan/inovasi dengan membuat alat kompor listrik untuk mencairkan malam yang dapat digunakan dengan mudah, alat yang simple yang dapat dibawa kemana-mana serta penggunaanya yang sederhana (Damayanti and Latifah, 2017; Khamid and Hasyim, 2017; Nurhayata, 2018; Asyari and Umar, 2019).

\section{METODE}

Pada tahap ini dilaksanakan survei dan wawancara kepada pemilik UMKM Batik Kalosa ibu Warsuni selaku mitra tempat dilaksanakannya PKM, yang terletak didaerah Karangploso, Kabupaten malang, guna membahas alat yang akan dibuat nanti dan keluhan apa saja yang dialami ketika menggunakan peralatan kompor konvensional demi menunjang produksi batik kain di Batik Kalosa.

\section{Pembuatan Jadwal}

Hal utama yang terpenting sebagai dasar alur pembuatan produk adalah penentuan langkah-langkah kerja yang diimplementasikan dengan pembuatan schedule. Dari sini setiap aktivitas dapat termonitoring dengan baik sehingga target yang ditentukan bisa tercapai. Format schedule yang dipakai menggunakan aplikasi microsoft office project, terlihat tracking alur pembuatan mulai tahap pembuatan desain sampai dengan pengujian produk. Seksi yang terlama yang menjadi kendala ada pada pembelian material. Beberapa permasalah datang pada pemilihan komponen elektronik yang spesifikasinya belum bisa mengcover kinerja kompor listrik yang diharapkan. Untuk meminimalisir schedule yang kemungkinan besar tidak sesuai target, kami menggunakan langkah bekerja yang sifatnya pararel. Artinya kami memaksimalkan proses perakitan komponen tanpa bergantung pada satu komponen yang statusnya belum terbeli. Berikut detail schedule pembuatan kompor listrik menggunakan aplikasi micrsoft office project seperti pada Gambar 1.

\section{Pembuatan desain dan penentuan material}

Setelah schedule terbuat langkah selanjutnya yang kami lakukan adalah pembuatan desain dan penentuan material kompor listrik. Untuk memudahkan pembuatan desain kami menggunakan software Autocad. Pentingnya mata kuliah gambar teknik dan praktikum Autocad khususnya pada jurusan teknik mesin sangat membantu kami dalam inovasi pembuatan produk. Disamping itu dengan penggunaan software tersebut kami bisa lebih mudah mensimulasikan pemilihan material yang sesuai dengan desain yang diharapkan. Gambar 2 adalah desain gambar hasil pembuatan kompor listrik menggunakan software Autocad. Sedangkan bentuk kompor listriknya adalah Gambar 3. 


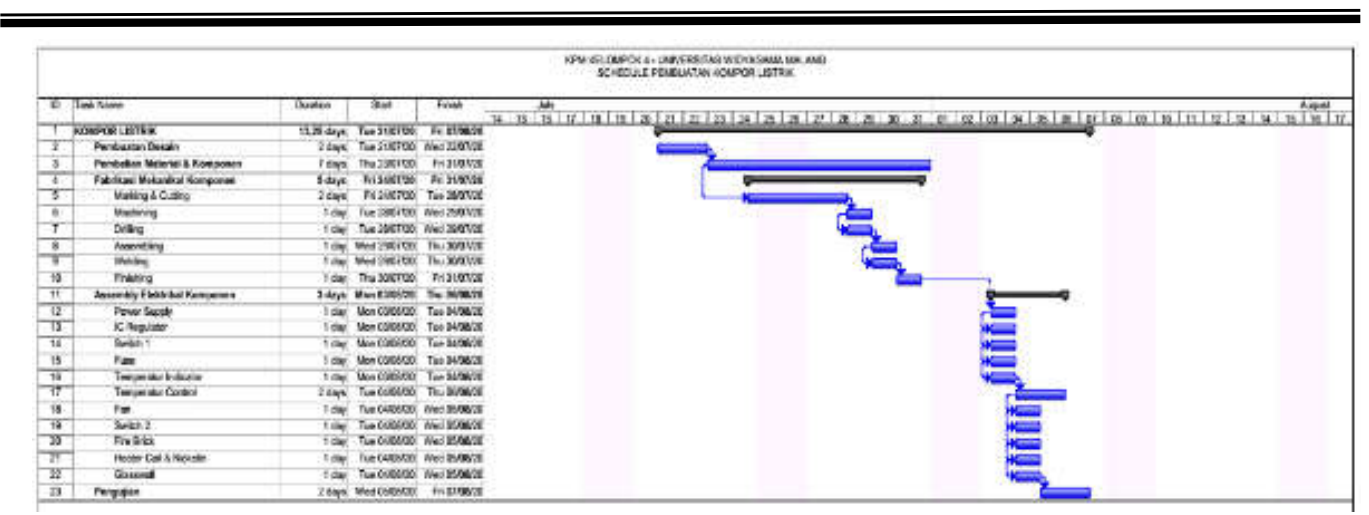

Gambar 1. Jadwal Pembuatan Kompor Listrik

Pada tahap pemilihan material ada beberapa alasan sebagai dasar penggunaan material yang dipakai, pemilihan material atau komponen kami bagi menjadi 2 jenis yaitu mekanikal material dan elektrikal komponen, untuk penjelasannya adalah sebagai berikut.

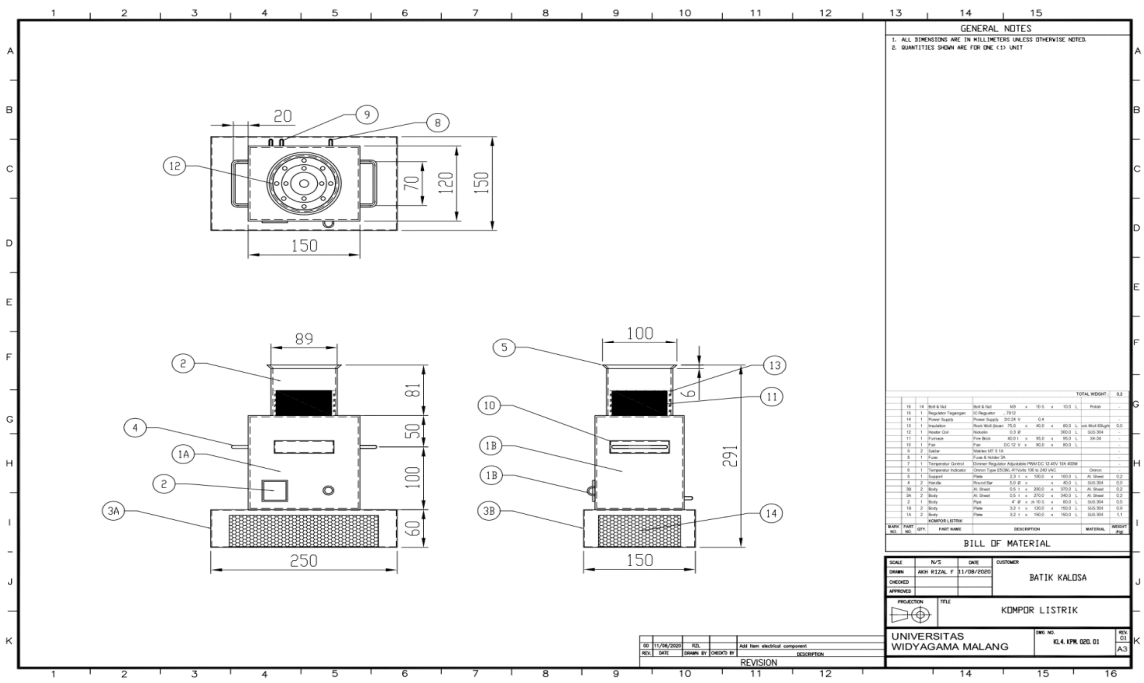

Gambar 2. Desain Kompor Listrik

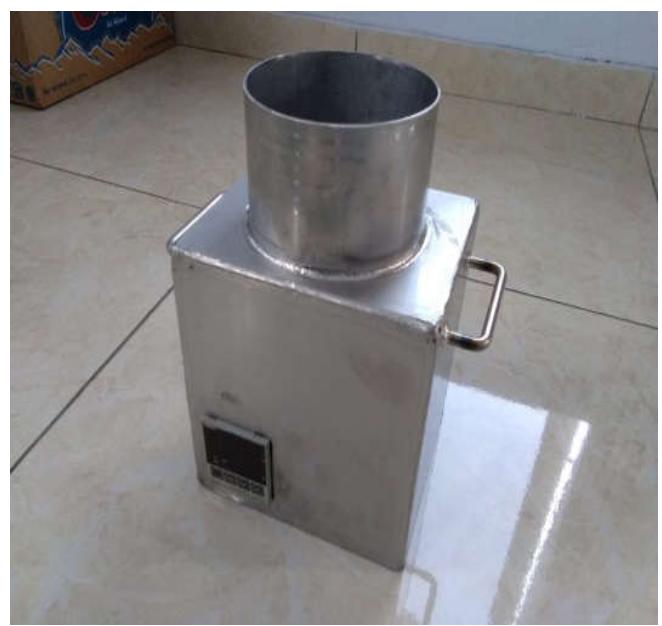

Gambar 3. Purwarupa Kompor Listrik 
Material

1. Bagian body menggunakan material Stainless steel SUS 304. Material stainless steel type 304 adalah stainless steel paling fleksibel dan banyak digunakan khususnya pada industri manukakturing sebagai peralatan tahan panas, food grade, dan korosi.

2. Bagian handle menggunakan profil Roundbar berbahan Stainless Steel. Sama halnya dengan bagian body pada bagian handle material stanless steel tetap menjadi pilihan karena kualitasnya yang tahan karat. Dimensi yang digunakan adalah Roundbar diameter $5 \mathrm{~mm}$.

3. Bagian body power supply menggunakan material alumunium sheet. Aluminium sheet adalah bahan logam berbentuk lembaran yang kuat, sangat cocok digunakan di daerah tropis karena memiliki sifat yang tahan terhadap segala cuaca serta tidak mudah terbakar.

4. Bagian untuk peletakan wajan menggunakan material alumunium sheet. Pada bagian ini terbuat dari alumunium sheet yang terletak pada bagian atas kompor.

5. Fire Brick atau batu tahan api dengan type SK-34 ukuran standard adalah $230 \times 114 \times$ $65 \mathrm{~mm}$.

6. Kabel power yang digunakan yaitu kabel NYAF $0.75 \mathrm{~mm}^{2}$.

7. Sekring adalah suatu pengaman/proteksi beban lebih serta proteksi bila terjadi konsleting, dan dipilih sebesar 3 Ampere.

8. Saklar power, digunakan untuk memutus dan menyambung sumber tegangan dengan komponen - komponen peralatan.

9. Temperature indikator digunakan sebagai tampilan monitoring kondisi aktual bagian yang akan dipanaskan, dengan temperature indikator maka pengguna dapat lebih mudah mengetahui berapa suhu panas yang dihasilkan oleh kompor listrik.

10. Termokopel adalah sensor suhu yang digunakan untuk mengukur suhu melalui dua jenis logam konduktor berbeda yang digabung pada ujungnya.

11. Power Supply adalah alat yang yang digunakan untuk mengkonversi tegangan dari 220 VAC PLN dirubah menjadi tegangan 24 VDC.

12. Elemen Pemanas terbuat dari bahan kawat nikelin ukuran $0.3 \mathrm{~mm}^{2}$, panjang 3 meter, dan tahanan $5 \mathrm{ohm}$.

13. IC Regulator berfungsi menurunkan tegangan output power supply dari 24 VDC menjadi $12 \mathrm{VDC}$, tegangan diturunkan dikarenakan input dari kipas blower menggunakan tegangan $12 \mathrm{VDC}$.

14. Kipas yaitu alat yang digunakan untuk proses konveksi dari panas yang dihasilkan oleh elemen pemanas menuju tungku pemanas melalui proses pemindahan panas dengan bantuan blower udara.

\section{Waktu Dan Tempat Pelaksaan Penelitian}

Nama Kegiatan : Kuliah Pengabdian Masyarakat (KPM) 2020

Pelaksana : Kelompok 4

Waktu : 19 juli - 16 Agustus 2020

Tempat : RT 17/RW 05, Dusun Leban, Desa Tawangargo, Kecamatan

Spesifikasi kompor listrik

$$
\text { Karangploso (seperti pada Gambar 4). }
$$
a. Max Power : $300 \mathrm{Watt}$
b. Input : AC 220 Volt
c. Output : DC 24 Volt
d. Max Temperatur: $125^{\circ} \mathrm{C}$
e. Dimension : $250 \times 150 \times 291 \mathrm{~mm}$
f. Weight : $3,2 \mathrm{Kg}$

\section{Cara Kerja Alat Kompor Listrik}

a. Kompor listrik menggunakan heater coil sebagai sumber panas utama

b. Proses perpindahan panas dilakukan secara konveksi

c. Desain body terbuat dari besi tahan karat / stainless steel 
d. Ada penambahan thermometer indicator untuk mengetahui suhu kerja

e. Aliran panas di hembuskan dengan bantuan kipas / fan

f. Tegangan diatur secara manual menggunakan Dimmer

g. Fire brick atau batu tahan api digunakan sebagai support dudukan coil

h. Rockwoll sebagai isolator untuk menjaga suhu body kompor tetap dingin saat dipegang.

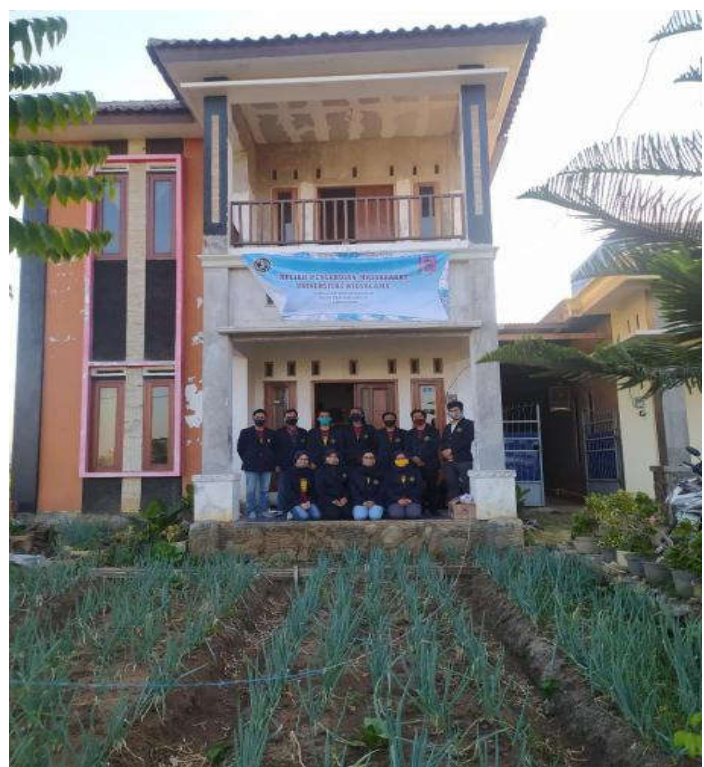

Gambar 4. Lokasi KPM di Batik Kalosa

\section{Penerapan}

Setelah melakukan wawancara dengan pemilik Batik Kalosa, permasalahan dari UMKM batik tersebut penggunaan kompor yang masih konvensional atau kompor yang berbahan bakar solar untuk melelehkan malam, dimana hal ini sangat berdampak terhadap besarnya biaya produksi dan asap yang dihasilkan dari pembakaran solar tersebut sangat berbahaya terhadap kesehatan pembatik jika digunakan secara terusmenerus. Dilakukan percobaan menggunakan kompor listrik dimana pada saat penggunaannya tidak perlu menggunakan korek api untuk memancing api. Hanya menekan tombol power dan mengatur supplay power untuk mencapai suhu titik lebur dengan melihat indikasi suhu yang ada di kompor listrik tersebut. Tidak ada asap yang dihasilkan oleh kompor listrik. Panas yang berlebihan pada kompor juga akan dideteksi oleh temperature controller dimana kipas akan bekerja, sehingga kompor listrik tidak terjadi panas yang berlebihan seperti pada Gambar 5.

\section{HASIL DAN PEMBAHASAN}

Hasil kuliah pengabdian masyarakat (KPM) ini berupa kompor listrik yang digunakan sebagai bentuk upaya kami dalam berinovasi maupun berguna bagi mitra "Batik Tulis Kalosa" karena pemilik mitra sangat mengapresiasi hasil kerja kami selama satu bulan. Setelah dilakukan percobaan pada saat menggunakan kompor konvensional dan kompor listrik didapat hasil:
a. Harga minyak tanah
: Rp 12.000,- per liter
b. Konsumsi minyak tanah
c. Biaya pembuatan kompor
: 3 liter (3 kompor) perhari
d. Konsumsi listrik kompor per hari: Rp 1.430 perhari 
Jika diasumsikan menggunakan minyak tanah perbulannya akan mengeluarkan uang sejumlah Rp. 1.080.000 dan apabila menggunakan kompor listrik akan mengeluarkan uang sejumlah Rp 42.900.

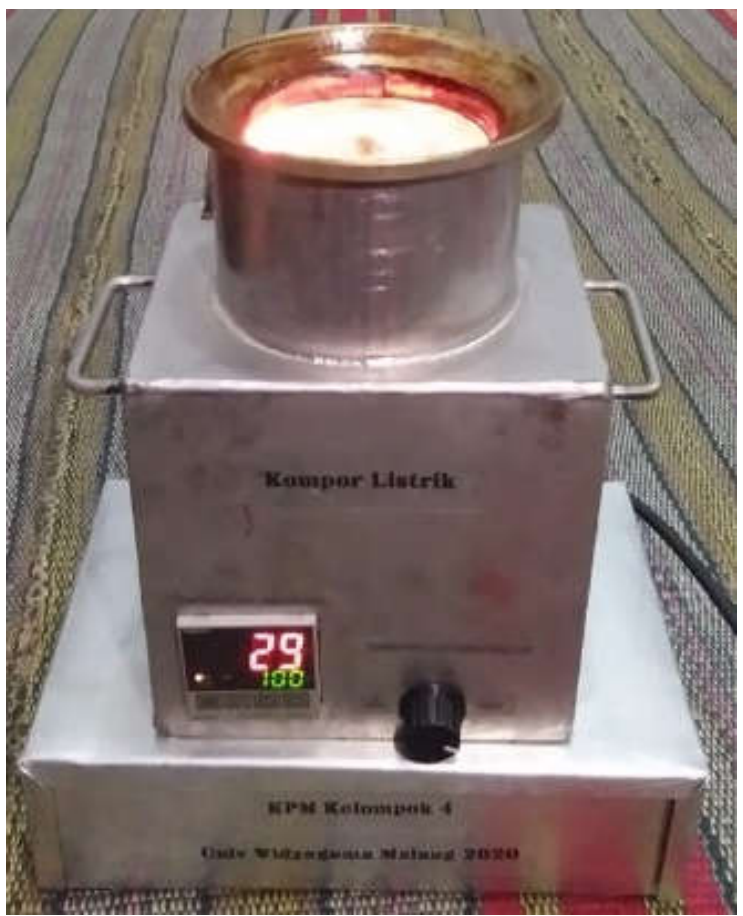

Gambar 5. Bentuk Kompor Listrik Hasil KPM Kelompok 4

\section{DAMPAK DAN MANFAAT}

Permasalahan pada Batik Kalosa tentang penggunaan kompor yang konvensional untuk melelehkan malam, memiliki biaya produksi yang cukup besar dan asap yang dihasilkan sangat berbahaya terhadap kesehatan pembatik. Dengan penggunaan kompor listrik tidak perlu menggunakan korek api untuk memancing api, tinggal menekan tombol power dan mengatur power supply untuk mencapai suhu titik lebur malam dengan melihat indikasi suhu yang ada di kompor listrik tersebut. Tidak ada asap yang dihasilkan oleh kompor listrik. Panas yang berlebihan pada kompor juga akan dideteksi oleh temperature kontroler sehingga kipas akan bekerja jika suhu terlalu tinggi. Kompor listrik telah dibuat dengan material pilihan, dan menghasilkan kompor yang lebih efisien dibandingkan menggunakan kompor konvensional.

\section{KESIMPULAN}

Kompor listrik telah dibuat dengan material pilihan, dan menghasilkan kompor yang lebih efisien dibandingkan menggunakan kompor konvensional, yang tidak menghasilkan asap dan mengganggu hasil produksi batik tulis. Kompor listrik ini telah diterapkan di rumah produksi Batik Kalosa, RT 17/RW 05, Dusun Leban, Desa Tawangargo, Kecamatan Karangploso, Kabupaten Malang.

\section{UCAPAN TERIMA KASIH}

Terimakasih kami ucapkan kepada Bu Warsunik dan Bu Jeky selaku pemilik Batik Kalosa yang sudah memberi ijin dan membantu menyelesaikan KPM ini. Bapak dan ibu 
staf LPPM dan para pimpinan Universitas Widyagama Malang, tidak lupa ucapan terima kasih disampaikan kepada teman-teman KPM anggota kelompok 4 yang sudah telah membantu menyelesaikan artikel ini.

\section{REFERENSI}

Andayani, S. and Tjahyono, E. (2014) 'Peningkatan Kuantitas Dan Kualitas Produk Pada Perajin Batik Dukuh Kupang Kota Surabaya', JPM17: Jurnal Pengabdian Masyarakat, 1(01).

Ari, W. and Nusantara, B. (2011) 'Makna Filosofis, Cara Pembuatan dan Industri Batik', Yogyakarta: Penerbit Andi.

Asyari, H. and Umar, U. (2019) 'Desain Prototipe Kompor Listrik Tenaga Surya', Emitor: Jurnal Teknik Elektro, 19(1), pp. 6-9.

Damayanti, M. and Latifah, L. (2017) 'Strategi Kota Pekalongan dalam pengembangan wisata kreatif berbasis industri batik', Jurnal Pengembangan Kota, 3(2), pp. 100-111.

Kartika, Y. and Mujanah, S. (2017) 'Ibm Kelompok Usaha Batik Di Kelurahan Sutorejo Kota Surabaya', JPM17: Jurnal Pengabdian Masyarakat, 2(03).

Khamid, A. and Hasyim, A. (2017) 'Desain Kompor Listrik Tenaga Surya untuk Batik Tulis yang Ramah Lingkungan'.

Lusianti, L. P. and Rani, F. (2012) 'Model Diplomasi Indonesia Terhadap UNESCO Dalam Mematenkan Batik Sebagai Warisan Budaya Indonesia Tahun 2009', Jurnal Transnasional, 3(02).

Nurhayata, I. G. (2018) 'Pengembangan Kompor Batik Listrik Otomatis Berbasis Mikrokontroller dengan Kontrol Sudut Fasa', in. Seminar Nasional Riset Inovatif, pp. 19-26.

Soesanto, S. (1980) 'Seni Kerajinan Batik Indonesia’, Yogyakarta: Balai Besar Kerajinan dan Batik. 